\title{
Removal of digesta components from the rumen of steers determined by sieving techniques and fluid, particulate and microbial markers
}

\author{
BY R. M. DIXON* AND L. P. MILLIGAN† \\ Department of Animal Science, University of Alberta, Edmonton, Canada T6G $2 P 5$
}

(Received 12 December 1983 - Accepted 10 October 1984)

1. When ${ }^{103} \mathrm{Ru}$-labelled Tris $\left(1,10\right.$-phenanthroline) ruthenium II chloride $\left({ }^{103} \mathrm{Ru}-\mathrm{P}\right)$ particulate marker in aqueous solution was added to the rumen of four steers given $5.5 \mathrm{~kg}$ grass hay $/ \mathrm{d}$ at two-hourly intervals, the distribution of ${ }^{103} \mathrm{Ru}-\mathrm{P}$ marker among rumen particles of various sizes was the same at $4 \mathrm{~h}, 3 \mathrm{~d}$ and $7 \mathrm{~d}$ after administration, the concentration of ${ }^{103} \mathrm{Ru}-\mathrm{P} / \mathrm{g}$ dry matter $(\mathrm{DM})$ was inversely related to particle size and 0.30 of the ${ }^{103} \mathrm{Ru}-\mathrm{P}$ was associated with the $\mathrm{DM}$ of particles too large to be moved from the rumen at a meaningful rate. Thus, fractional outflow rate (FOR) of ${ }^{103} \mathrm{Ru}-\mathrm{P}$ would reflect, but was not a direct measure of, the FOR of the small particle pool in the rumen.

2. When rumen digesta were labelled with ${ }^{103} \mathrm{Ru}-\mathrm{P}$, placed in nylon cloth bags and incubated in vitro with unlabelled digesta, $59 \%$ of the ${ }^{103} \mathrm{Ru}-\mathrm{P}$ disappeared from the nylon bag in $24 \mathrm{~h}$, and $74 \%$ in $48 \mathrm{~h}$. Similar results were obtained when large particles (retained by a $3.2 \mathrm{~mm}$ mesh screen during wet sieving) from rumen digesta were subjected to this procedure.

3. In a further experiment, the steers were given the hay in either the long or ground form and drinking water to which $10 \mathrm{~g}$ sodium chloride/ 1 were, or were not, added.

4. The FOR of ${ }^{51} \mathrm{CrEDTA}$ in centrifuged rumen fluid was increased $(P<0.05)$ from 1.78 to $2.10 / \mathrm{d}$ by grinding of the hay diet, but was not influenced by the intake of an additional $257 \mathrm{~g} \mathrm{NaCl} / \mathrm{d}$. The FOR values of ${ }^{103} \mathrm{Ru}-\mathrm{P}$ in mixed rumen digesta and organic ${ }^{35} \mathrm{~S}$ in micro-organisms were linearly correlated $(P<0.05)$ and were not affected $(P>0.05)$ by grinding and salt treatments. On average, the FOR of organic ${ }^{35} \mathrm{~S}$ in micro-organisms was 0.41 of that of ${ }^{5} \mathrm{C}$ CrEDTA in centrifuged rumen fluid and 0.85 of that of ${ }^{103} \mathrm{Ru}-\mathrm{P}$ in rumen digesta respectively.

5. Grinding of the hay did not $(P>0.05)$ change the proportion of rumen DM $(0.476-0.515)$ or faecal DM $(0 \cdot 107-0 \cdot 153)$ retained by the $3.2 \mathrm{~mm}$ mesh and larger screens.

6. FOR from the rumen of a given size group of particles was calculated as the ratio, estimated daily flow from the rumen of the size group: rumen pool of the group. With increasing particle size there was a progressive decline in FOR; values of FOR for groups of particles greater than $4.0 \mathrm{~mm}$ were negligible. If the rumen DM was considered to behave as two pools, the $3.2 \mathrm{~mm}$ mesh screen appeared to be an appropriate division between the large-particle and the small-particle DM pools.

7. FOR of lignin present in mixed rumen digesta was 0.48 of the mean of the FOR values of the particle groups of the small-particle pool, while the FOR of lignin present in the small-particle pool was 0.92 of the mean small-particle FOR.

The rate of removal of digesta components from the rumen influences the extent and type of fermentation (Sutherland, 1976; Bull et al. 1979), intake of poorly digested forages (Balch \& Campling, 1962) and efficiency of microbial synthesis (Harrison \& McAllan, 1980). Measurement of rate of removal of particulate material from the rumen has been undertaken using stained particles (Blaxter et al. 1956) or adsorbable markers, but these techniques are subject to difficulties in interpretation (Faichney \& Griffiths, 1978; Ellis et al. 1979; Dixon et al. 1983). Alternatively, by considering the rumen contents as a single kinetic pool, Minson (1966) measured a total turnover rate equal to the sum of rate of digestion and rate of outflow, while Faichney (1980) employed an approach that was conceptually similar to estimate the fractional outflow rate (FOR) of constituents from the rumen. However, the latter methods do not take into account the presence in the rumen pool of particles of dimensions that may be too large to pass readily from the rumen (Hungate, 1966; Pearce, 1967; Evans et al. 1973). Description of the effect of particle size

\footnotetext{
* Present address: School of Agriculture and Forestry, University of Melbourne, Victoria 3052, Australia.
}

† For reprints. 
on passage from the rumen should permit a more complete understanding of the regulation of particulate movement and control of intake.

The FOR of water may influence the FOR of small particles and of micro-organisms, since water is likely to be the vehicle by which these are transported from the rumen (Hungate, 1966). In a number of studies, addition of soluble salts to the diet has been used as a means to increase the FOR of water from the rumen (Harrison et al. 1975; Faichney et al. 1980-1981) and would, therefore, appear to offer a means of detecting a possible relation between movements of fluid, micro-organisms and small rumen particles.

The present study with cattle had several objectives. First, it was intended to obtain more information on the behaviour in the rumen of the particulate marker ${ }^{103} \mathrm{Ru}$-labelled Tris (1,10-phenanthroline) ruthenium II chloride $\left({ }^{103} \mathrm{Ru}-\mathrm{P}\right)$. Second, the size distribution of rumen digesta and faecal particles was used to estimate the FOR from the rumen of particles of various sizes, and these FOR values were compared with the FOR of ${ }^{103} \mathrm{Ru}-\mathrm{P}$ and lignin particulate markers. Third, the interactions between the FOR from the rumen of ${ }^{51} \mathrm{CrEDTA}$, ${ }^{103} \mathrm{Ru}-\mathrm{P}$ and organic ${ }^{35} \mathrm{~S}$ as water, particulate and microbial markers respectively, were examined in steers given ground or long hay with or without addition of sodium chloride. The opportunity was also taken to compare calculations of the FOR of water and particulate markers from the rumen based on rumen and faecal sampling sites.

\section{MATERIALS AND METHODS}

Four steers ( 24 months of age, predominantly Charolais, $309-343 \mathrm{~kg}$ ) were prepared with 100-mm diameter rumen cannulas (Hecker, 1969). Anthelmintic (Thibenzole; Merck, Sharpe \& Dohme, Pointe Claire, Canada) was administered 6 weeks before the experiments commenced and vitamins A (225 mg retinol), D (2.75 mg cholecalciferol) and E (75 mg D- $\alpha$-tocopherol acetate) (Vitamin A-D-E, Dominion Veterinary Laboratories, Winnipeg, Canada) were injected intramuscularly at intervals of 6 weeks.

The steers were given $5.5 \mathrm{~kg}$ mature grass hay $/ \mathrm{d}$ which consisted of approximately equal parts of Bromus inermis, Festuca rubra and Phleum pratense. The hay contained $891 \mathrm{~g}$ dry matter (DM)/kg air-dry material and $931 \mathrm{~g}$ organic matter, $13.7 \mathrm{~g}$ nitrogen, $719 \mathrm{~g}$ neutraldetergent fibre and $422 \mathrm{~g}$ acid-detergent fibre $/ \mathrm{kg}$ DM. Cobalt mineralized salt blocks (Canadian Salt Ltd, Montreal, Canada) and water were available at all times.

\section{Expt 1}

The four steers were held in metabolism crates in a room with continuous lighting and given the grass hay in long form at two-hourly intervals for 2 weeks before and during the experiment. A single injection of $0.3 \mathrm{mCi}{ }^{103} \mathrm{Ru}-\mathrm{P}$ prepared from ${ }^{103} \mathrm{RuCl}_{3}$ (Amersham International plc, Amersham, Bucks) by the method of Tan et al. (1971) in $750 \mathrm{ml}$ aqueous solution was administered into the rumen of each steer.

Digesta were sampled from the lower ventral sac of the rumen $4 \mathrm{~h}, 3.0 \mathrm{~d}$ and $7.0 \mathrm{~d}$ after administration of the dose, using a tube $(35 \mathrm{~mm}$ i.d.) which could be occluded at the lower end by a conical stopper, and was immediately fractionated. A subsample of rumen digesta was squeezed through cheesecloth and the suspension of small particles thus obtained was designated 'fines'. A sample of this suspension was centrifuged $(14000 \mathrm{~g}, 15 \mathrm{~min})$ to isolate a microbial fraction using the procedures of Nolan \& Leng (1972).

Rumen digesta were fractionated into various particle-size groups using a wet sieving procedure. The sieving apparatus consisted of a cylinder $110 \mathrm{~mm}$ in diameter with a screen fixed in one end. This cylinder was placed in a beaker, $180 \mathrm{~mm}$ in diameter, and 2.5 litres tap-water were added. The sample (approximately $7.5 \mathrm{~g} \mathrm{DM}$ ) of wet digesta was placed inside the cylinder and the slurry manually stirred in a rotary fashion using a spatula ( $25 \mathrm{~mm}$ 
wide) while the cylinder with the screen fixed at the bottom was slowly lifted manually within the beaker. The up-down cycle with stirring was carried out five times using the same water and the particulate material retained on the screen was quantitatively transferred to a dish for drying. The slurry that passed through the first screen was then sieved using successively smaller screen mesh sizes; mesh sizes used in succession were $6 \cdot 8,3 \cdot 2,2 \cdot 0,1 \cdot 0,0 \cdot 7,0 \cdot 5$ and $0.25 \mathrm{~mm}$. The ${ }^{103} \mathrm{Ru}-\mathrm{P}$ radioactivity $/ \mathrm{g} \mathrm{DM}$ of each of the fractions was determined using a gamma spectrometer (Model 8000, Beckman Instruments, Fullerton, California).

The ${ }^{103} \mathrm{Ru}-\mathrm{P}$ radioactivity in each isolated fraction of rumen digesta was expressed as a proportion of the ${ }^{103} \mathrm{Ru}-\mathrm{P}$ radioactivity in microbial DM obtained from the same steer at the same time. The proportion of total ${ }^{103} \mathrm{Ru}-\mathrm{P}$ associated with each particle group in the rumen was calculated from the concentration in each sieved fraction and using the weights of each particle-size group in the rumen measured in Expt 3 for the same steers fed on the same diet. The ${ }^{103} \mathrm{Ru}-\mathrm{P}$ radioactivity in the DM which passed through the $0.25 \mathrm{~mm}$ mesh screen was assumed to equal that measured for the 'fines' DM that passed through cheesecloth.

\section{Expt 2}

Two samples of approximately $35 \mathrm{~g}$ of mixed rumen digesta obtained from a steer given the grass hay were mixed with $0.6 \mu \mathrm{Ci}{ }^{103} \mathrm{Ru}-\mathrm{P}$ in $5 \mathrm{ml}$ water and were left in an open beaker at room temperature for $20 \mathrm{~h}$. Each preparation of labelled digesta was then transferred into a nylon bag(made from HSO 13 nylon filter cloth, pore size $47 \times 47 \mu \mathrm{m}$; Henry Simon Ltd, Stockport, Cheshire). The top of the bag was tied and the free liquid was expressed by hand and discarded. Rumen digesta obtained from the same steer were squeezed through a single layer of cheesecloth and 300-ml portions of the suspension of fine particles thus obtained were placed in beakers, Each nylon bag containing a ${ }^{103} \mathrm{Ru}$-P-labelled digesta preparation was placed in one of the beakers and was stirred manually at frequent intervals. The fine particle suspension was sampled $(10 \mathrm{~g})$ from the beaker for the following $23 \mathrm{~h}$. The nylon bag containing the digesta was then removed from its beaker, rinsed with distilled water and transferred to a second beaker containing a new suspension of fine particles. Stirring was continued and samples were taken from the second beaker at intervals for the following $25 \mathrm{~h}$. Finally the nylon bag was removed, rinsed and the bag and contents transferred to a vial for radioactivity measurements.

A procedure similar to that described previously was performed in which $1.2 \mu \mathrm{Ci}{ }^{103} \mathrm{Ru}-\mathrm{P}$ in $5 \mathrm{ml}$ water were added to each of two $50 \mathrm{~g}$ samples of wet digesta. After standing for $20 \mathrm{~h}$, particles retained by a $3.2 \mathrm{~mm}$ mesh screen were isolated from both samples and transferred to nylon bags. These bags were stirred while suspended in beakers of fine particles from rumen digesta and sampling and counting were done as described previously for the mixed rumen digesta.

The ${ }^{103} \mathrm{Ru}-\mathrm{P}$ present in the suspension of fine particles in the beaker was calculated from the concentration of radioactivity and the total amount of DM, with correction for the removal of ${ }^{103} \mathrm{Ru}-\mathrm{P}$ in samples. The ${ }^{103} \mathrm{Ru}-\mathrm{P}$ in the nylon bag at any specific time was calculated as (total amount of label in the bag and associated with the fine particles at the end of the experiment) minus (label associated with the suspension of fine particles at the time of sampling).

\section{Expt 3}

Experimental treatments and procedures. The four steers were given either long hay or ground hay with free access to either tap-water or water containing $10 \mathrm{~g} \mathrm{NaCl} / 1$ (salt water) within a $4 \times 4$ Latin square design. Baled hay was used for the long-hay treatment, while grinding was achieved using a hammermill with a $4.7 \mathrm{~mm}$ screen.

For days $1-15$ of each period the steers were held in individual pens to allow adaptation to the diets. On day 16 the steers were moved to metabolism crates with continuous lighting 
and temperature control $\left(20-25^{\circ}\right)$ and the hay was given in equal portions at two-hourly intervals. Measurements of consumption of fresh water and salt water and of salt blocks were commenced. On day 21 jugular catheters were inserted.

At 09.00 hours on day 22 a single injection of ${ }^{51} \mathrm{Cr}$ complexed with EDTA $\left({ }^{51} \mathrm{CrEDTA}\right.$, $1 \mathrm{mCi}, 0 \cdot 1 \mathrm{~g} \mathrm{Cr} / \mathrm{mCi}$, prepared by the method of Binnerts et al. (1968); New England Nuclear, Boston, MA, USA), ${ }^{103} \mathrm{Ru}-\mathrm{P}(0.1 \mathrm{mCi})$ and $\mathrm{Na}_{2}{ }^{35} \mathrm{SO}_{4}\left(0.75 \mathrm{mCi}, 1 \mathrm{~g} \mathrm{Na}_{2} \mathrm{SO}_{4} / \mathrm{mCi}\right.$; New England Nuclear) in $750 \mathrm{ml}$ water was made into the ventral sac of the rumen.

Six samples of blood and rumen digesta were obtained at approximately two-hourly intervals following administration of markers. Samples of rumen digesta were taken from the ventral sac as in Expt 1. The liquid obtained by straining digesta through cheesecloth was immediately centrifuged $\left(14000 \mathrm{~g}, 5^{\circ}, 15 \mathrm{~min}\right)$ and the supernatant fraction stored at $5^{\circ}$ pending analysis for ${ }^{51} \mathrm{Cr}$ and osmolality. Blood sampled from the jugular catheter was centrifuged $(5000 \mathrm{~g}, 15 \mathrm{~min})$ and the plasma stored $\left(5^{\circ}\right)$ for subsequent osmolality analysis.

Eleven samples of rumen digesta from the ventral sac were also obtained using the sampling probe at $6 \mathrm{~h}$, and at 12-h intervals thereafter for $5 \mathrm{~d}$ following administration of the markers. A portion of each mixed digesta sample was stored at $-20^{\circ}$ for subsequent determination of ${ }^{51} \mathrm{Cr}$ and ${ }^{103} \mathrm{Ru}$. Also, rumen digesta were immediately strained through cheesecloth and a microbial sample was isolated from $30 \mathrm{ml}$ of the liquid by differential centrifugation (Nolan \& Leng, 1972). The microbes were washed once with $30 \mathrm{ml}$ $0.05 \mathrm{M}$-sodium sulphide plus $0.05 \mathrm{M}-\mathrm{Na}_{2} \mathrm{SO}_{4}$ and then twice with $0.15 \mathrm{M}-\mathrm{NaCl}$, the cells being recovered by centrifugation $\left(14000 \mathrm{~g}, 5^{\circ}, 15 \mathrm{~min}\right)$ after each washing.

Eight samples of faeces were obtained at 12-h intervals between 3 and $7 \mathrm{~d}$ following administration of markers and stored at $-20^{\circ}$ for subsequent determination of ${ }^{51} \mathrm{Cr}$ and ${ }^{103} \mathrm{Ru}$. Total collections of faeces were made daily between days 21 and 28 .

On one occasion, between days 28 and 32, the time each steer spent ruminating was measured between 14.00 and 22.00 hours by means of a water-filled balloon, placed under the jaw, connected to a pressure transducer.

On day 33 or day 34 the rumen of each steer was emptied commencing $1 \mathrm{~h}$ after the previous feed. The rumen contents were weighed, thoroughly mixed and subsampled for determination of DM. While the rumen was empty, each steer given the tap-water treatment was given $1 \mathrm{~kg}$ ground or long hay and the consequent boluses of masticated feed were quantitatively collected at the cardia.

Laboratory procedures. The DM of feed, rumen digesta and faeces were determined by drying at $70^{\circ}$. Osmolalities of centrifuged rumen fluid and plasma were determined by freezing point depression using an osmometer (Model 5002, Osmette A; Precision Systems, Newton, MA, USA).

${ }^{51} \mathrm{Cr}$ and ${ }^{103} \mathrm{Ru}$ in centrifuged rumen fluid, rumen digesta and faeces were determined using the gamma spectrometer described previously (see p. 349). The specific radioactivity of organic ${ }^{35} \mathrm{~S}$ in micro-organisms was determined by the method of Bird \& Fountain (1970) using a commercial scintillation cocktail (ACS, Amersham International) and a liquid scintillation counter (Model 6880, Mark III; Searle, Des Plaines, Ill, USA) with an external standard for quench correction.

The particle size distribution of DM of feed before ingestion, masticated feed in swallowed boluses, rumen digesta obtained from emptying the rumen and in faeces was determined in duplicate using the wet sieving procedure described for Expt 1, except that a $4.0 \mathrm{~mm}$ mesh screen was also used. Feed samples were soaked in water overnight, while samples of boluses and faeces were added directly to the sieving apparatus. The particles sedimented by centrifugation $\left(14000 \mathrm{~g}, 5^{\circ}, 15 \mathrm{~min}\right)$, and the soluble DM with correction for the solutes in tap-water, were determined for duplicate $100-\mathrm{ml}$ subsamples of the slurry which passed through the $0.25 \mathrm{~mm}$ mesh screen. Only the $6 \cdot 8,4 \cdot 0$ and $3.2 \mathrm{~mm}$ mesh screens 
were used for boluses and the proportion of DM which passed through the $3 \cdot 2 \mathrm{~mm}$ mesh screen was calculated by difference.

Repeatability of wet sieving was examined by sieving six subsamples of rumen contents (20-25 $\mathrm{g}$ wet digesta obtained from a sheep fed on coarsely-chopped lucerne (Medicago sativa) hay) through a screen $45 \mathrm{~mm}$ in diameter. Screen mesh sizes of $4.0 \mathrm{~mm}$ and $1.0 \mathrm{~mm}$ were used, and the proportion of particulate DM which passed through the $1.0 \mathrm{~mm}$ mesh screen was determined by centrifugation $\left(20000 \mathrm{~g}, 5^{\circ}, 15 \mathrm{~min}\right)$. The percentage of particulate DM retained by the $4.0 \mathrm{~mm}$ screen was 29.5 (coefficient of variation (CV) $6.3 \%$ ), by the $1.0 \mathrm{~mm}$ screen $37.6(\mathrm{CV} 4.2 \%)$ and passing through the $1.0 \mathrm{~mm}$ screen $32.8(\mathrm{CV} 3.8 \%$ ).

Concentrations of lignin in rumen digesta large particles (DM in the 6.8, 4.0-6.8 and $3 \cdot 2-4 \cdot 0 \mathrm{~mm}$ mesh particle-size groups), small particles (DM in the $2 \cdot 0-3 \cdot 2,1 \cdot 0-2 \cdot 0,0 \cdot 7-1 \cdot 0$, $0.5-0.7$ and $0.25-0.5 \mathrm{~mm}$ mesh particle-size groups), mixed rumen digesta, feed and faeces were determined by the method of Goering \& Van Soest (1970).

Calculations. When the decline in concentration of each marker with time at each sample site was considered, a first-order kinetic equation always described more than $93 \%$ of the variance and, in ninety-one of the ninety-six regression lines, more than $97 \%$ of the variance. Consequently, the FOR of each marker from the rumen was calculated as the first-order rate-constant of the pool. Rumen DM pool size was calculated from the intercept of ${ }^{103} \mathrm{Ru}-\mathrm{P}$ concentration at zero time (Shipley \& Clark, 1972).

The fractional turnover rate of the large-particle pool of the rumen was calculated (Poppi et al. $1981 \mathrm{~b}$ ) as the ratio, daily entry of large-particle DM (i.e. retained by the $3.2 \mathrm{~mm}$ mesh and larger screens) into the rumen in ingestion boluses: the rumen large-particle DM pool. FOR to the small intestine of each particle-size group from the rumen was calculated as the ratio, daily flow of the particle-size-group DM from the rumen:rumen DM pool size for that group. Flow of each particle-size group was estimated from the faecal flow of that particle-size-group DM and by assuming that 0.2 of total apparent DM digestion in the steer occurred post-ruminally (Kennedy, 1982) and that this digestion was not influenced by particle size.

FOR of lignin in mixed rumen digesta was calculated (Poppi et al. 1981 a) as the ratio, daily faecal lignin output:total lignin present in the rumen contents. FOR of lignin in the small-particle pool of the rumen was calculated as the ratio, daily faecal lignin : total amount of lignin in the rumen that was in small particles.

Statistical analysis. Differences between treatments were compared by analysis of variance, and the Newman-Keuls range test was used to separate the means into their respective classes. Comparisons between the FOR of ${ }^{51} \mathrm{CrEDTA}$ and ${ }^{103} \mathrm{Ru}-\mathrm{P}$ markers measured at different sampling sites, and between DM pool sizes determined with ${ }^{103} \mathrm{Ru}-\mathrm{P}$ or by emptying the rumen, were made using a paired $t$ test (Snedecor \& Cochran, 1967).

\section{RESULTS \\ Expt 1}

The ${ }^{103} \mathrm{Ru}-\mathrm{P}$ concentration in each particle group relative to the concentration on microbial DM did not differ $(P>0.05)$ at $4 \mathrm{~h}, 3 \mathrm{~d}$ and $7 \mathrm{~d}$ after dosing of ${ }^{103} \mathrm{Ru}-\mathrm{P}$ into the rumen (Table 1). ${ }^{103} \mathrm{Ru}-\mathrm{P}$ concentration progressively increased from 0.22 to 0.49 of that of microbial DM as the size of particles decreased from those retained by the $6.8 \mathrm{~mm}$ mesh screen to the $0.25-0.5 \mathrm{~mm}$ mesh particle-size group. The 'fines' obtained after squeezing through cheesecloth had ${ }^{103} \mathrm{Ru}-\mathrm{P}$ concentrations that were $0.64-0.75$ that of microbial DM.

The majority of ${ }^{103} \mathrm{Ru}-\mathrm{P}$ in the rumen was associated with particulate matter passing through the $0.25 \mathrm{~mm}$ screen $(0.51)$ and DM passing retained by the $6.8 \mathrm{~mm}$ mesh screen $(0 \cdot 27)$. 
Table 1. Expt 1. ${ }^{103}$ Ru-labelled Tris (1,10-phenanthroline) ruthenium II chloride $\left({ }^{103} \mathrm{Ru}-P\right)$ concentration in microbial dry matter $(D M)$ and in various particle-size groups of rumen digesta isolated by wet sieving relative to the concentration in microbial DM

(Samples were obtained $4 \mathrm{~h}, 3 \mathrm{~d}$ and $7 \mathrm{~d}$ after administration in aqueous solution of ${ }^{103} \mathrm{Ru}-\mathrm{P}$ into the rumen of four steers)

\begin{tabular}{|c|c|c|c|c|c|c|}
\hline & \multirow{2}{*}{$\begin{array}{l}\text { Particle } \\
\text { size group } \\
(\mathrm{mm})\end{array}$} & \multicolumn{3}{|c|}{ Sampling times } & \multirow[b]{2}{*}{ Mean } & \multirow{2}{*}{$\begin{array}{l}\text { Proportion of } \\
\text { total }{ }^{103} \mathrm{Ru}-\mathrm{P} \\
\text { in rumen DM }\end{array}$} \\
\hline & & $4 \mathrm{~h}$ & $3 \mathrm{~d}$ & $7 \mathrm{~d}$ & & \\
\hline $\begin{array}{l}{ }^{103} \text { Ru-P concentration in } \\
\text { microbial DM (counts } / \mathrm{min} \\
\text { per } \mathrm{g} \mathrm{DM} \text { ) }\end{array}$ & - & 15389 & 1283 & 88 & - & - \\
\hline $\begin{array}{l}{ }^{103} \mathrm{Ru}-\mathrm{P} \text { concentration } \\
\text { relative to }{ }^{103} \mathrm{Ru}-\mathrm{P} \\
\text { concentration in } \\
\text { microbial DM }\end{array}$ & $\begin{array}{c}>6.8 \\
3 \cdot 2-6 \cdot 8 \\
2 \cdot 0-3 \cdot 2 \\
1 \cdot 0-2 \cdot 0 \\
0.7-1.0 \\
0.5-0.7 \\
0 \cdot 25-0.5 \\
\text { Fines* }\end{array}$ & $\begin{array}{l}0.21 \\
0.23 \\
0.29 \\
0.28 \\
0.35 \\
0.37 \\
0.46 \\
0.75\end{array}$ & $\begin{array}{l}0.23 \\
0.25 \\
0.28 \\
0.32 \\
0.38 \\
0.32 \\
0.50 \\
0.74\end{array}$ & $\begin{array}{l}0.22 \\
0.32 \\
0.22 \\
0.33 \\
0.23 \\
0.49 \\
0.53 \\
0.64\end{array}$ & $\begin{array}{l}0.22 \\
0 \cdot 27 \\
0.26 \\
0.31 \\
0.32 \\
0.40 \\
0.49 \\
0.71\end{array}$ & $\begin{array}{l}0.27 \\
0.03 \\
0.04 \\
0.06 \\
0.02 \\
0.02 \\
0.04 \\
0.51\end{array}$ \\
\hline SEM & & - & - & - & $0 \cdot 08$ & 一 \\
\hline
\end{tabular}

* Filtrate obtained by squeezing rumen digesta through cheesecloth and would, therefore, include free-floating micro-organisms.

\section{Expt 2}

Transfer of ${ }^{103} \mathrm{Ru}-\mathrm{P}$ from within nylon bags to the surrounding suspension of fine particles is shown in Fig $1(a)$ for ${ }^{103} \mathrm{Ru}$-P-labelled mixed rumen digesta and in Fig. $1(b)$ for ${ }^{103} \mathrm{Ru}-\mathrm{P}-\mathrm{labelled}$ large particles. With mixed rumen digesta, there was a loss of $37 \%$ of the total ${ }^{103} \mathrm{Ru}-\mathrm{P}$ over the first $4 \mathrm{~h}$, followed by a less rapid rate of loss so that at the end of $24 \mathrm{~h} 59 \%$ of the ${ }^{103} \mathrm{Ru}-\mathrm{P}$ had been transferred out of the nylon bag. When the fine particle suspension was replaced after $24 \mathrm{~h}$, there was further movement of ${ }^{103} \mathrm{Ru}-\mathrm{P}$ such that $74 \%$ of the initial ${ }^{103} \mathrm{Ru}-\mathrm{P}$ was transferred out of the nylon bag. Very little of this second phase of movement occurred during the final $17 \mathrm{~h}$. The results for transfer of ${ }^{103} \mathrm{Ru}-\mathrm{P}$ from the labelled large particles were similar except that the movement was not as great: $24 \%$ of the label was transferred during the first $4 \mathrm{~h}$ and $61 \%$ over the $48 \mathrm{~h}$.

\section{Expt 3}

Effects of salt consumption and FOR of markers. Water intake and urine were increased $(P<0.01)$ by offering water containing $10 \mathrm{~g} \mathrm{NaCl} / 1$ (Table 2$)$. The salt treatment caused no change in plasma osmolality (mean $277 \mathrm{mosmol} / \mathrm{kg}$ ) but increased $(P<0 \cdot 01)$ the osmolality of rumen fluid from 274 to $289 \mathrm{mosmol} / \mathrm{kg}$. Consequently, the osmotic gradient from the plasma to the rumen fluid increased $(P<0 \cdot 01)$ from $-3 \mathrm{mosmol} / \mathrm{kg}$ to $+11 \mathrm{mosmol} / \mathrm{kg}$.

The FOR of ${ }^{51}$ CrEDTA measured in centrifuged rumen fluid (mean 1.94/d) was greater $(P<0.01)$ than the FOR of this marker measured in mixed rumen digesta (mean $1 \cdot 18 / \mathrm{d})$, which in turn was greater $(P<0.01)$ than the FOR of ${ }^{51} \mathrm{CrEDTA}$ estimated from the rate of decline in faeces (mean $0.93 / \mathrm{d}$ ).

The FOR of ${ }^{51} \mathrm{CrEDTA}$ in centrifuged rumen fluid was not influenced by salt ingestion but was greater $(P<0.05)$ in steers given ground hay $(2 \cdot 10 / \mathrm{d})$ than in steers given long hay $(1 \cdot 78 / \mathrm{d})$. The rumen water volume determined by emptying the rumen was not influenced by treatment. Flow of water from the rumen tended to be greater $(P<0 \cdot 10)$ in 


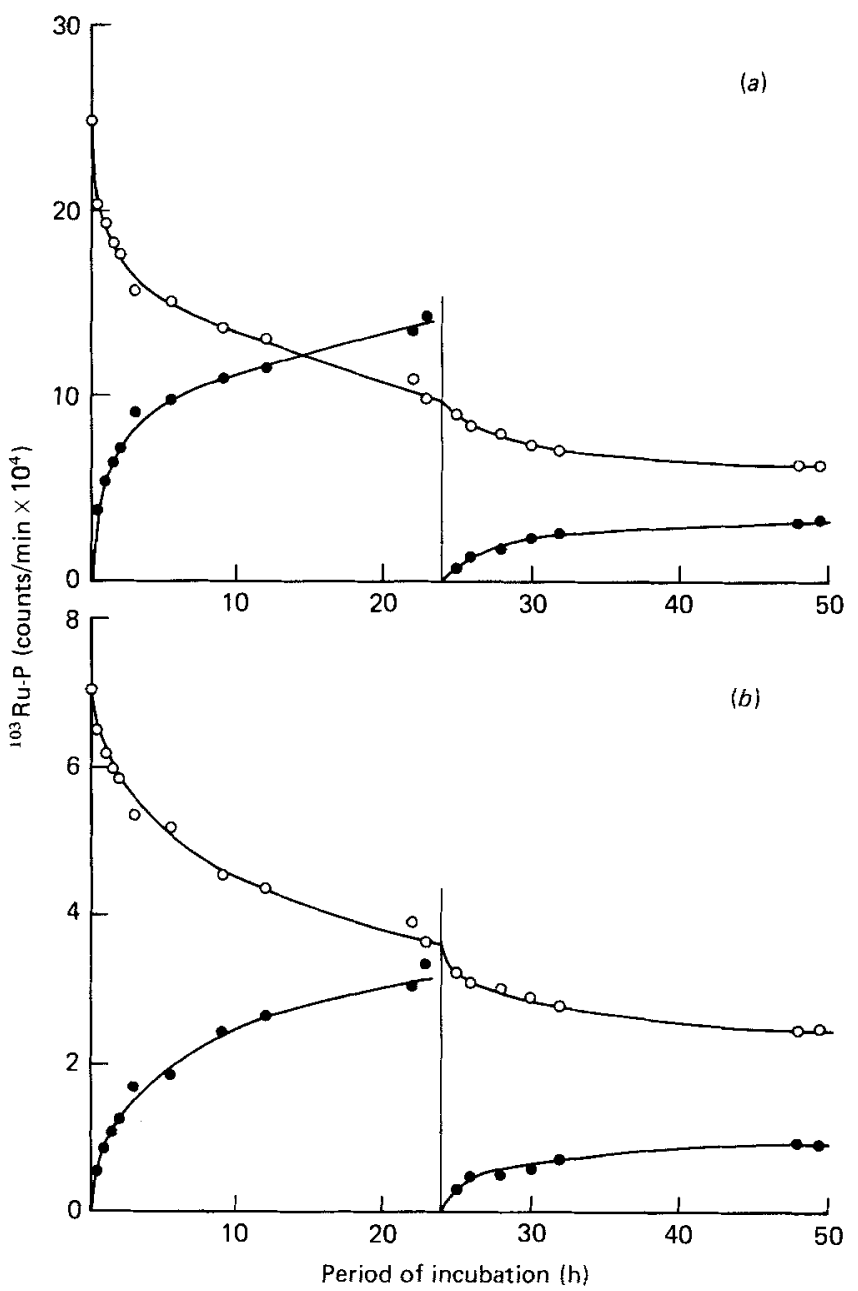

Fig. 1. In vitro rate of transfer of ${ }^{103} \mathrm{Ru}$-labelled Tris $(1,10$-phenanthroline) ruthenium II chloride $\left({ }^{103} \mathrm{Ru}-\mathrm{P}\right.$; counts/min) from digesta in nylon bags $(O)$ into a surrounding suspension of fine particles of rumen fluid (O) over $48 \mathrm{~h}$ in Expt 2 . The suspension of fine particles was replaced after $24 \mathrm{~h} .{ }^{103} \mathrm{Ru}-\mathrm{P}$ was initially attached to $(a)$ mixed rumen digesta or $(b)$ large particles from rumen digesta.

steers given ground hay $(97.9$ litres/d) than in steers given long hay $(81.3$ litres/d); there was no consistent effect $(P>0.05)$ of ingestion of salt water.

The FOR of ${ }^{103} \mathrm{Ru}-\mathrm{P}$ measured in mixed rumen digesta (mean $0.93 / \mathrm{d}$ ) was greater $(P<0.05)$ than this FOR calculated from the change in ${ }^{103} \mathrm{Ru}-\mathrm{P}$ concentration in faeces $(0.89 / \mathrm{d})$. The quantity of DM in the rumen measured by emptying the rumen $(5.42 \mathrm{~kg})$ was greater $(P<0.01)$ than the DM pool size calculated from the ${ }^{103} \mathrm{Ru}-\mathrm{P}$ distribution $(4.65 \mathrm{~kg})$. Neither the FOR of ${ }^{103} \mathrm{Ru}-\mathrm{P}$ nor the rumen content of DM measured by emptying the rumen was affected by the treatments (Table 2).

The FOR of organic ${ }^{35} \mathrm{~S}$ in rumen micro-organisms (mean $0.79 / \mathrm{d}$ ) was not affected by the dietary treatments (Table 2). This FOR was, on average, 0.41 of the FOR of ${ }^{51}$ CrEDTA measured in centrifuged rumen fluid but there was no significant correlation between the 
Table 2. Expt 3. Measurements for four steers given either long or ground grass hay and either tap-water or water containing $10 \mathrm{~g}$ sodium chloride $/ \mathrm{l}$

\begin{tabular}{|c|c|c|c|c|c|c|c|c|}
\hline & \multicolumn{2}{|c|}{ Ground hay } & \multicolumn{2}{|c|}{ Long hay } & \multirow[b]{2}{*}{ SEM } & \multicolumn{3}{|c|}{ Statistical significance of effect } \\
\hline & $\begin{array}{c}\text { Tap- } \\
\text { water }\end{array}$ & $\begin{array}{c}\text { Salt } \\
\text { water }\end{array}$ & $\begin{array}{l}\text { Tap- } \\
\text { water }\end{array}$ & $\begin{array}{c}\text { Salt } \\
\text { water }\end{array}$ & & $\begin{array}{c}\text { Hay } \\
\text { treatment }\end{array}$ & $\begin{array}{l}\text { Water } \\
\text { treatment }\end{array}$ & $\begin{array}{l}\text { Inter- } \\
\text { action }\end{array}$ \\
\hline Water intake $(1 / d)$ & $22-8$ & $25 \cdot 9$ & $21 \cdot 4$ & $29 \cdot 3$ & 0.6 & NS & ** & * \\
\hline Urine output $(\mathrm{l} / \mathrm{d})$ & $6 \cdot 3$ & $12-0$ & 4.8 & $13 \cdot 3$ & 0.4 & NS & ** & NS \\
\hline Salt intake $(\mathrm{g} / \mathrm{d})$ & 25 & 269 & 36 & 306 & 7 & NS & ** & NS \\
\hline $\begin{array}{l}\text { Rumen osmotic } \\
\text { pressure (mosmol/kg) }\end{array}$ & 271 & 287 & 277 & 291 & 1.6 & NS & $* *$ & NS \\
\hline $\begin{array}{l}\text { Rumen-plasma osmotic } \\
\text { gradient (mosmol } / \mathrm{kg} \text { ) }\end{array}$ & $-4 \cdot 7$ & $9 \cdot 0$ & $-0 \cdot 5$ & $12 \cdot 8$ & $1 \cdot 4$ & NS & $* *$ & NS \\
\hline $\begin{array}{l}\text { Period of time } \\
\text { ruminating }(\mathrm{h} / 8 \mathrm{~h})\end{array}$ & $1 \cdot 33$ & 0.93 & $2 \cdot 09$ & $2 \cdot 63$ & $0 \cdot 13$ & $* *$ & NS & $*$ \\
\hline DM digestibility & 0.595 & 0.601 & 0.574 & 0.597 & 0.004 & NS & $*$ & NS \\
\hline \multicolumn{9}{|l|}{$\begin{array}{l}\text { FOR of }{ }^{51} \mathrm{CrEDTA} \\
\text { determined from: }\end{array}$} \\
\hline $\begin{array}{l}\text { Centrifuged rumen } \\
\text { fluid }(/ \mathrm{d})\end{array}$ & 2.06 & $2 \cdot 13$ & $1 \cdot 81$ & 1.76 & 0.09 & * & NS & NS \\
\hline $\begin{array}{l}\text { Mixed rumen } \\
\text { digesta }(/ \mathrm{d})\end{array}$ & 1.29 & $1 \cdot 11$ & $1 \cdot 16$ & $1 \cdot 16$ & $0 \cdot 04$ & NS & NS & NS \\
\hline Faeces $(/ d)$ & 1.01 & $0 \cdot 86$ & 0.94 & 0.91 & 0.03 & NS & NS & NS \\
\hline $\mathrm{Wt}$ rumen water $(\mathrm{kg}) \dagger$ & $45 \cdot 1$ & $48 \cdot 3$ & $45 \cdot 0$ & $46 \cdot 1$ & $1 \cdot 7$ & NS & NS & NS \\
\hline $\begin{array}{l}\text { Water outflow from } \\
\text { the rumen }(1 / \mathrm{d})\end{array}$ & $92 \cdot 9$ & $102 \cdot 9$ & $81 \cdot 5$ & $81 \cdot 1$ & $5 \cdot 1$ & NS & NS & NS \\
\hline \multicolumn{9}{|l|}{$\begin{array}{l}\text { FOR of }{ }^{103} \mathrm{Ru}-\mathrm{P} \\
\text { determined from }\end{array}$} \\
\hline $\begin{array}{c}\text { Mixed rumen } \\
\text { digesta }(/ \mathrm{d})\end{array}$ & 0.98 & $0 \cdot 86$ & 0.93 & 0.94 & 0.04 & NS & NS & NS \\
\hline Faeces $(/ \mathrm{d})$ & 0.90 & 0.84 & 0.90 & 0.92 & 0.03 & NS & NS & NS \\
\hline Wt rumen $\mathrm{DM}(\mathrm{kg}) \dagger$ & $5 \cdot 14$ & $5 \cdot 41$ & $5 \cdot 45$ & 5.69 & $0 \cdot 20$ & NS & NS & NS \\
\hline $\begin{array}{l}\text { Rumen DM determined } \\
\text { from }{ }^{103} \mathrm{Ru}-\mathrm{P} \text { pool } \\
\text { size }(\mathrm{kg})\end{array}$ & 4.49 & $5 \cdot 19$ & $4 \cdot 71$ & $4 \cdot 23$ & $0 \cdot 22$ & NS & NS & NS \\
\hline $\begin{array}{l}\text { FOR of organic }{ }^{35} S \text { in } \\
\text { rumen microbes }(/ d)\end{array}$ & $0 \cdot 83$ & 0.76 & $0 \cdot 75$ & $0 \cdot 80$ & 0.04 & NS & NS & NS \\
\hline
\end{tabular}

DM, dry matter; FOR, fractional outflow rate; ${ }^{103} \mathrm{Ru}-\mathrm{P},{ }^{103} \mathrm{Ru}$-labelled Tris (I,10-phenanthroline) ruthenium II chloride; NS, not significant.

${ }^{*} P<0.05, * * P<0.01$.

$\dagger$ Determined by emptying the rumen.

FOR of these two markers $(r 0.45, n 16, P>0.05)$. The FOR of organic ${ }^{35} S$ in micro-organisms $\left(\left[{ }^{35} \mathrm{~S}\right]\right.$ FOR $)$ was on average 0.85 of the FOR of ${ }^{103} \mathrm{Ru}-\mathrm{P}$ determined in mixed rumen digesta $\left[{ }^{103} \mathrm{Ru}-\mathrm{P}\right]$ and these values were linearly correlated $(P<0.05):\left[{ }^{35} \mathrm{~S}\right]$ FOR $=0.0996+0.741\left[{ }^{103} \mathrm{Ru}-\mathrm{P}\right]$ FOR $(n 16 ; r 0.70 ;$ residual SD 0.0977$)$.

Particle size distribution and the FOR of various particle groups. In the steers given tap-water the distribution between the $6.8,4.0$ and $3.2 \mathrm{~mm}$ mesh screens of ingesta bolus DM was markedly different between the diets of long hay and of ground hay (Table 3). The $6.8 \mathrm{~mm}$ mesh screen retained 0.438 of total DM of boluses of the long hay but only 0.072 of the DM of the boluses of ground hay. The proportions of total bolus DM of the diet of ground hay in the $4 \cdot 0-6.8 \mathrm{~mm}$ and $3 \cdot 2-4.0 \mathrm{~mm}$ mesh particle groups and that which passed through the $3.2 \mathrm{~mm}$ mesh screen were greater $(P<0.05)$ than those for ingestion boluses of long hay. During ingestion, mastication of ground hay reduced the proportion of DM in large 
Table 3. Expt 3. Distribution of dry matter (DM) in various particle groups determined by wet sieving of boluses, rumen digesta and faeces of four steers receiving tap-water and given either long or ground grass hay

\begin{tabular}{|c|c|c|c|c|}
\hline \multirow{2}{*}{$\begin{array}{c}\text { Screen mesh } \\
\text { size (mm) of } \\
\text { particle groups }\end{array}$} & \multicolumn{2}{|c|}{ Diet } & \multirow[b]{2}{*}{ SEM } & \multirow{2}{*}{$\begin{array}{c}\text { Statistical } \\
\text { significance } \\
\text { of difference }\end{array}$} \\
\hline & Ground hay & Long hay & & \\
\hline \multicolumn{5}{|l|}{ Boluses: } \\
\hline$>6.8$ & 0.072 & 0.438 & 0.030 & ** \\
\hline $4 \cdot 0-6 \cdot 8$ & 0.232 & 0.119 & 0.026 & * \\
\hline $3 \cdot 2-4 \cdot 0$ & $0 \cdot 106$ & 0.036 & 0.004 & $* *$ \\
\hline$<3 \cdot 2$ & 0.590 & 0.407 & 0.014 & $* *$ \\
\hline \multicolumn{5}{|l|}{ Rumen digesta: } \\
\hline$>6.8$ & 0.230 & 0.392 & 0.041 & * \\
\hline $4 \cdot 0-6 \cdot 8$ & 0.176 & 0.082 & 0.014 & ** \\
\hline $3 \cdot 2-4 \cdot 0$ & 0.070 & 0.041 & 0.003 & $* *$ \\
\hline $2 \cdot 0-3 \cdot 2$ & 0.082 & 0.055 & 0.005 & $*$ \\
\hline $1 \cdot 0-2 \cdot 0$ & 0.090 & 0.078 & 0.012 & NS \\
\hline $0.7-1.0$ & 0.031 & 0.029 & 0.003 & NS \\
\hline $0.5-0.7$ & 0.023 & 0.021 & 0.002 & NS \\
\hline $0.25-0.5$ & 0.030 & 0.031 & 0.004 & NS \\
\hline$<0.25$ & 0.132 & 0.133 & 0.015 & NS \\
\hline Soluble DM & 0.137 & 0.139 & 0.018 & NS \\
\hline \multicolumn{5}{|l|}{ Faeces: } \\
\hline$>6.8$ & 0.009 & 0.004 & 0.002 & NS \\
\hline $4 \cdot 0-6 \cdot 8$ & 0.064 & 0.050 & 0.025 & NS \\
\hline $3 \cdot 2-4 \cdot 0$ & 0.080 & 0.053 & 0.008 & $*$ \\
\hline $2 \cdot 0-3 \cdot 2$ & $0 \cdot 134$ & 0.131 & 0.009 & NS \\
\hline $1 \cdot 0-2 \cdot 0$ & $0 \cdot 183$ & 0.217 & 0.012 & NS \\
\hline $0 \cdot 7-1 \cdot 0$ & 0.062 & 0.074 & 0.007 & NS \\
\hline $0.5-0.7$ & 0.050 & $0 \cdot 054$ & 0.012 & NS \\
\hline $0.25-0.5$ & 0.081 & 0.096 & 0.004 & NS \\
\hline$<0.25$ & $0 \cdot 243$ & 0.241 & 0.026 & NS \\
\hline Soluble DM & 0.094 & 0.080 & 0.011 & NS \\
\hline
\end{tabular}

NS, not significant.

$* P<0.05,{ }^{* *} P<0.01$.

particles (retained on the $3.2 \mathrm{~mm}$ sieve) from 0.518 to 0.410 , with most of the reduction occurring for the material retained by the $6.8 \mathrm{~mm}$ mesh screen. For long hay, reduction of the proportion of DM in large particles from 1.000 to 0.593 in ingestion boluses demonstrated a much greater breakdown by mastication.

The steers given long hay had a greater $(P<0.05)$ proportion of rumen DM retained by the $6.8 \mathrm{~mm}$ mesh screen and less $(P<0.05) \mathrm{DM}$ in the $4.0-6.8 \mathrm{~mm}, 3 \cdot 2-4.0 \mathrm{~mm}$ and $2 \cdot 0-3 \cdot 2 \mathrm{~mm}$ mesh particle groups than did those given ground hay (Table 3). Faecal particle size distribution did not differ with diet. Large particles accounted for $0 \cdot 107-0.153$ of faecal DM, while the smallest particles $(<0.25 \mathrm{~mm})$ plus the soluble fraction comprised $0 \cdot 321-0 \cdot 337$ of faecal DM.

The fractional turnover rate of the rumen large particle pool was greater $(P<0.05)$ for the steers given long hay $(1.07 / \mathrm{d})$ than for those given ground hay $(0.82 / \mathrm{d})$; this was associated with a tendency for a greater pool of large particles $(2.81 \mathrm{~kg} \mathrm{DM} v .2 .45 \mathrm{~kg} \mathrm{DM})$.

There were large differences in FOR from the rumen calculated for the various particle groups (Fig. 2). The FOR of the particles retained by the $6.8 \mathrm{~mm}$ mesh screen was negligible 


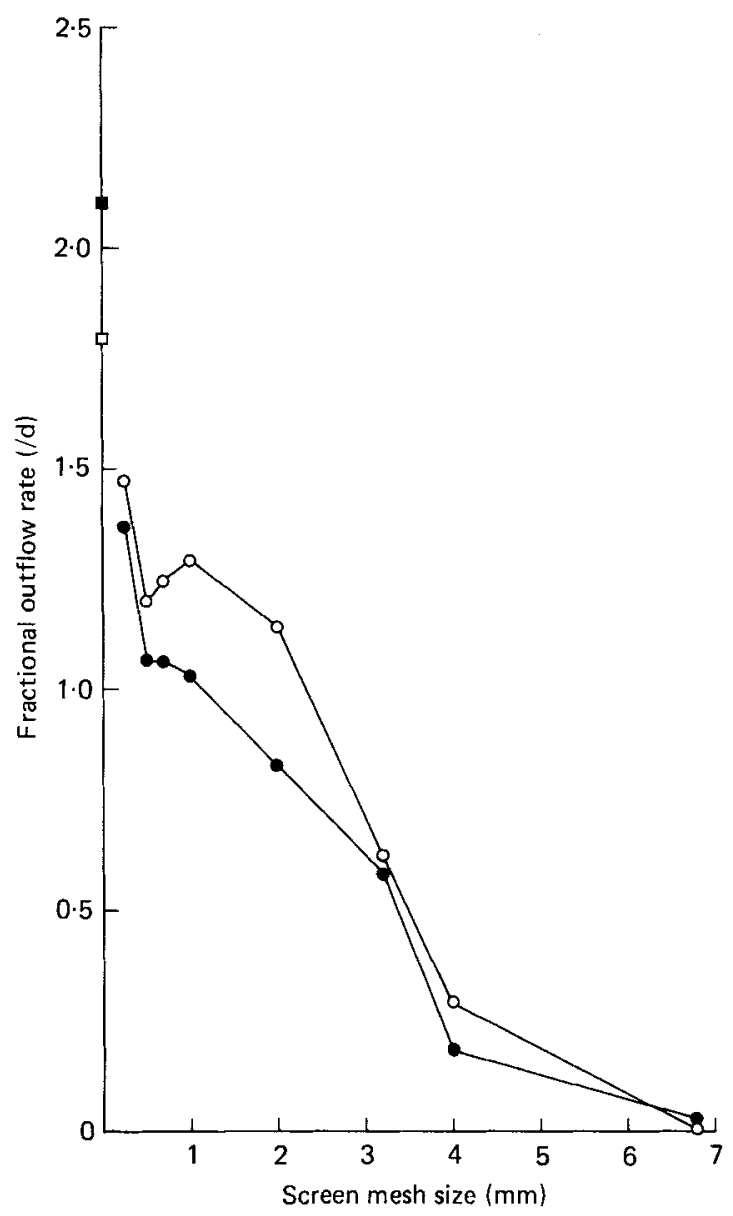

Fig. 2. Fractional outflow rate from the rumen of particles retained by screens of decreasing mesh sizes in steers given long $(O)$ or ground $(O)$ hay in Expt 3 (SEM 0.14). The fractional outflow rate of soluble dry matter is assumed to equal that of ${ }^{51} \mathrm{CrEDTA}$ ( $\square$, long; $\square$, ground) determined in centrifuged rumen fluid.

and there was a progressive increase in the FOR of particle groups of successively smaller mesh sizes. Means calculated for the two diets reveal a large increase in FOR from the $4.0-6.8 \mathrm{~mm}$ mesh particle group $(0.23 / \mathrm{d})$ to the $2 \cdot 0-3.2 \mathrm{~mm}$ mesh particle group $(0.99 / \mathrm{d})$ and a further increase to the $0.25-0.5 \mathrm{~mm}$ mesh particle group $(1.41 / \mathrm{d})$. The FOR calculated for particulate DM that passed through the $0.25 \mathrm{~mm}$ mesh screen was $0.86 / \mathrm{d}$ which is only 0.61 of the FOR of the $0.25-0.5 \mathrm{~mm}$ group and is inconsistent with the preceeding apparent inverse relation of FOR and particle size. The value of the FOR calculated for soluble DM was $0.36 / \mathrm{d}$ which is only $0 \cdot 19$ of the FOR of water and is not logical. Extensive intestinal digestion and absorption of microbial cells and soluble molecules would result in faecal recovery of the particles passing the $0.25 \mathrm{~mm}$ screen and soluble DM being very low relative to the amounts of the fractions leaving the rumen. As a result, FOR values of these fractions were likely to have been underestimated and incorrect and are not presented in Fig. 2. The FOR of the $0.25-0.5 \mathrm{~mm}$ mesh were 0.81 and 0.66 of the FOR of water when steers drinking tap-water were given long and ground hay respectively (Fig. 2). 


\section{DISCUSSION \\ Particle sieving technique}

The method of wet sieving used in the present study in which a sample was manually stirred in a rotary fashion as a screen was lifted through a large volume of water would tend to orient the long axis of particles parallel to the screen surface. Consequently, the material retained by a given screen size in the present study would tend to reflect the largest dimension of the particles. The mechanical sieving techniques used in other studies where the orientations of particles and screens may be different (Jones \& Moseley, 1977; Poppi et al. 1980 ) could result in the material retained by a given screen size reflecting the smaller dimensions of particles. Consequently, differences in particle size distributions measured using different sieving techniques may, to a large extent, reflect differences in the basis of selectivity of the techniques rather than actual particle size differences between experiments. For this reason comparisons of particle size distribution with other studies using different sieving techniques are of questionable validity.

\section{${ }^{103} \mathrm{Ru}-\mathrm{P}$ kinetics in the rumen}

The results of Expt 1 showed that, after ${ }^{103} \mathrm{Ru}-\mathrm{P}$ was injected into the rumen in aqueous solution, a constancy of its distribution between particle groups was maintained for days. This indicated that the rate of migration of ${ }^{103} \mathrm{Ru}-\mathrm{P}$ between particle groups was greater than the rate of passage of ${ }^{103} \mathrm{Ru}-\mathrm{P}$ from the rumen. In agreement with previous studies (Faichney \& Griffiths, 1978; Dixon et al. 1983), Expt 2 showed that ${ }^{103} \mathrm{Ru}-\mathrm{P}$ migrated readily between particles. Although ${ }^{103} \mathrm{Ru}-\mathrm{P}$ will leave the rumen in association with small particles, its FOR may not equal the average of the small particle pool. Association of some ${ }^{103} \mathrm{Ru}-\mathrm{P}$ with large particles $(0.30$ in the present experiment), essentially unable to leave the rumen, would cause the ${ }^{103} \mathrm{Ru}-\mathrm{P}$ FOR to be less than the FOR of the small-particle pool. Association of a large proportion $(0.51$ in the present experiment $)$ of ${ }^{103} \mathrm{Ru}-\mathrm{P}$ with the very small particles, for which we do not have a reliable FOR estimate, constitutes a serious unknown; if the pattern of more rapid flow with decreasing particle size did extend to those passing the $0.25 \mathrm{~mm}$ screen, the ${ }^{103} \mathrm{Ru}-\mathrm{P}$ FOR would be accelerated by movement with this fraction. It would be expected then that the ratio, FOR of ${ }^{103} \mathrm{Ru}-\mathrm{P}$ : FOR of the small-particle pool, would be subject to variation as a result of any factor that might result in a change in distribution of ${ }^{103} \mathrm{Ru}-\mathrm{P}$ among the various size groups of rumen digesta particles.

\section{Effect of sampling site on the FOR calculated for ${ }^{51} \mathrm{CrEDTA}$ and ${ }^{103} \mathrm{Ru}-\mathrm{P}$}

${ }^{51} \mathrm{CrEDTA}$ has been used extensively as a marker of the fluid phase of digesta in the rumen (Faichney, 1975; Faichney et al. 1980-1981) and the large and significant differences between the FOR of ${ }^{51} \mathrm{CrEDTA}$ from the rumen determined from the change in ${ }^{51} \mathrm{Cr}$ radioactivity with time in centrifuged rumen fluid, rumen digesta or faeces are in contrast to previous studies (Grovum \& Williams, 1973; Lemerle et al. 1980). Furthermore, the volume of rumen fluid calculated from the initial distribution of ${ }^{51} \mathrm{Cr}$ in centrifuged rumen fluid was much greater than that determined directly by emptying the rumen. Although we cannot provide a substantiated explanation, these anomalies in the ${ }^{51} \mathrm{CrEDTA}$ results could have arisen if there was association of a portion of the ${ }^{51} \mathrm{Cr}$ with the particulate phase of rumen digesta. In vitro experiments using the same batch of ${ }^{51} \mathrm{CrEDTA}$ indicated that $19-22 \%$ of the ${ }^{51} \mathrm{Cr}$ associated with particulate matter sedimented by centrifugation (20000 $\mathrm{g}, 15 \mathrm{~min}$ ), despite repeated washing and regardless of addition of carrier CrEDTA. Attachment of ${ }^{51}$ CrEDTA (Warner, 1969), CrEDTA (Poppi et al. 1981 $a$ ) and of ${ }^{58}$ CoEDTA (Kennedy et al. 1982) to digesta particles has been observed previously. Although the ${ }^{51} \mathrm{CrEDTA}$ used in the present experiment was specified as greater than $99.0 \%$ radionuclidic 
and radiochemical purity by the supplier, if any cationic ${ }^{51} \mathrm{Cr}$ were present, it would associate with particulate matter. When ${ }^{51} \mathrm{CrCl}_{3}$ of high specific radioactivity and in aqueous solution was administered into the rumen of sheep, only 9-12\% remained in the centrifuged rumen supernatant fraction (R. M. Dixon and P. Fenn, unpublished results), presumably due to radiocolloidal absorption similar to that observed for the rare earth cations (Ellis et al. 1979). The FOR of ${ }^{51} \mathrm{CrEDTA}$ in centrifuged rumen fluid would have been a valid measure of the FOR of rumen fluid if any attachment of ${ }^{51} \mathrm{Cr}$ to particulate matter occurred immediately after addition of the ${ }^{51} \mathrm{Cr}$ into the rumen and if the attachment was irreversible.

The FOR of ${ }^{103} \mathrm{Ru}-\mathrm{P}$ measured in rumen digesta was $4 \%$ greater than this value determined from faecal samples, indicating that faecal samples could be used to obtain an acceptable estimate. However, the $14 \%$ underestimate of rumen pool size using ${ }^{103} \mathrm{Ru}-\mathrm{P}$ is of concern. Since there was an inverse relation between particle size and concentration of ${ }^{103} \mathrm{Ru}-\mathrm{P} / \mathrm{g}$ DM in rumen digesta (Expt 1), the error may have been caused by preferential sampling of small-particle DM from the rumen.

\section{Effects of dietary treatments on FOR of water, particulate matter and micro-organisms}

The inclusion of $10 \mathrm{~g} \mathrm{NaCl} / 1$ in drinking water produced no apparent ill-effects in the steers. All steers continued to consume the entire ration of hay as it was offered and osmolalities of plasma and of urine were not affected by the ingested salt.

The absence of an effect of salt ingestion on FOR of ${ }^{51}$ CrEDTA in centrifuged rumen fluid or outflow of water from the rumen indicated that if the elevated osmotic gradient between plasma and rumen fluid increased net transepithelial water flow (Dobson et al. 1970,1976 ), the flow of saliva was reduced correspondingly. The absence of a measurable response of water outflow to salt ingestion is consistent with the report of Kellaway et al. (1978) but in contrast to the study of Rogers et al. (1979) in which a similar amount of salt increased rumen water volume by $14 \%$ and FOR by $17 \%$ in steers fed on a diet consisting predominantly of lucerne hay. Inconsistencies between experiments with sheep have also been reported (Tomas \& Potter, 1975; Faichney et al. 1980-1981).

The increase in FOR of ${ }^{51} \mathrm{CrEDTA}$ in centrifuged rumen fluid with grinding of the feed in the present experiment is in agreement with the results of Beever et al. (1981) who reported that the FOR of rumen water was increased by $11 \%$ on grinding of dried Lolium multiflorum or Phleum pratense given to sheep. Since there was little influence on the distribution of $\mathrm{DM}$ among the various particle groups of rumen digesta, the similar FOR of ${ }^{103} \mathrm{Ru}-\mathrm{P}$ for the diets of long and ground hay suggest that there was little change in the FOR of the small-particle pool. Consequently, it appeared that the increased water FOR in response to grinding of the hay was not associated with an increased FOR of the small-particle pool.

The FOR of organic ${ }^{35} \mathrm{~S}$ in micro-organisms has been used previously to estimate the FOR of micro-organisms from the rumen (Walker \& Nader, 1975; Kennedy, 1982). In the present study, the FOR of organic ${ }^{35} \mathrm{~S}$ in micro-organisms was correlated with the FOR of ${ }^{103} \mathrm{Ru}-\mathrm{P}$, but not with the FOR of ${ }^{51} \mathrm{CrEDTA}$, which initially suggests that the flow of micro-organisms from the rumen was influenced more by the passage of particulate matter than of water. Alternatively, the correlation might be due to substantial association of ${ }^{103} \mathrm{Ru}-\mathrm{P}$ with microbial cells; a greater concentration of ${ }^{103} \mathrm{Ru}-\mathrm{P}$ in microbial DM than in rumen digesta particulate DM was observed.

\section{Large- and small-particle pools in the rumen}

Several authors have proposed that the DM present in the rumen can be represented as a two-pool system of large- and small-particle DM pools (Hungate, 1966; Poppi et al. $1981 \mathrm{~b}$ ). Although the present study demonstrated that there was not a clearly discernible size below which all particles were equally likely to leave the rumen, a two-pool model of 
small- and large-particle pools is likely to be a useful simplification in describing particulate matter in the rumen. Only $0 \cdot 107-0 \cdot 153$ of faecal particulate DM was retained by the $3 \cdot 2$ $\mathrm{mm}$ mesh and larger screens (Table 2) and the FOR of particulate DM retained by the 3.2 mm mesh screen was low compared with smaller particles (Fig. 2). Therefore, for the sieving techniques used, it was concluded that the DM retained by the $3.2 \mathrm{~mm}$ mesh screen provided an appropriate definition of the large-particle pool.

\section{Turnover of the large-particle pool in the rumen}

The fractional turnover rate of the rumen large-particle pool would be equal to the sum of the rate constants of digestion of large-particle DM and of mechanical breakdown of large particles to small particles. These processes were more rapid for the steers given long hay $(1.07 / \mathrm{d})$ than for those given ground hay $(0.82 / \mathrm{d})$ and this was associated with a reduction in rumination time on the latter diet from 2.36 to $1.13 \mathrm{~h} / 8 \mathrm{~h}$ observation interval. This is consistent with other evidence that chewing during rumination is primarily responsible for reduction of the size of large particles in the rumen (Pearce \& Moir, 1964; Milligan et al. 1980; Van Soest, 1982).

\section{Passage of particles from the rumen}

The method used to calculate the FOR of the various particle groups from the rumen depended on several assumptions.

First, it was considered that each particle group in the rumen could be represented as a homogeneous first-order kinetic pool. Observations in numerous experiments, including the present study, that disappearance from the rumen of fluid, particulate and microbial markers and stained particles are well described by first-order kinetics suggests that this assumption did not introduce appreciable error.

Second, it was assumed that the particle size distribution in digesta flowing from the rumen was the same as that in faeces. Poppi et al. (1980) observed a similar particle size distribution in abomasal digesta and faeces for particles retained by $0.15 \mathrm{~mm}$ mesh or greater screens. As noted previously, it is probable that there is extensive intestinal digestion and absorption of very small particles (including microbial cells) and soluble molecules resulting in calculation of low FOR of these fractions.

Third, it was assumed in the calculations that 0.80 of total DM digestion occurred in the rumen and that this was not influenced by grinding the hay. The proportion of total digestible organic matter digested in the rumen in cattle given forage diets has been estimated as 0.71-0.82 for oaten chaff (Redman et al. 1980), 0.79 for wheat straw (Sriskandarajah et al. 1982), 0.82-0.89 for Hetropogon contortus hay (Hunter \& Siebert, 1980 ) and $0.80-0.93$ for mixed grass-legume hay (Kennedy, 1982). The assumption of a constant 0.80 in the present experiment undoubtedly caused some error in the estimate of the quantity of a particle-size group leaving the rumen and this error would proportionally carry through the calculation of FOR. To the extent that the smaller particles leaving the rumen may be the more digestible, the true FOR of smaller particles may be even greater relative to those of larger particles and the differences in FOR from the rumen due to particle size could be more extreme than shown in Fig. 2. Furthermore, although in sheep, grinding of a diet of grass hay may reduce the proportion of total digestion occurring in the rumen (Beever et al. 1972), a large change in site of digestion apparently only occurs with grasses with a high content of soluble carbohydrates (Beever et al. 1981). In the present experiment it was expected that the sun-cured mature grass hay given to the steers would have a low content of soluble carbohydrates, and the absence of any difference in overall digestibility also suggested that any change in site of digestion due to grinding of the hay was small. However, because of the possibility of a change in DM outflow from the rumen due to 
grinding, it was considered inappropriate to compare values of FOR from the rumen for the long- and ground-hay diets.

The quantity of a particle group in the faeces is governed by both the rate constant (FOR) of movement from the rumen of that particle group and by the pool size of the particles in the rumen. FOR can therefore be considered to describe the likelihood, or ease, of particle movement from the rumen. The approximately linear decrease in the rumen FOR between $0.25-0.5 \mathrm{~mm}$ and $4.0-6.8 \mathrm{~mm}$ mesh particle groups (Fig. 2) is in agreement with observation of a linear increase in rumen retention time with increasing diameter of plastic particles (Campling \& Freer, 1962) and the gradational change in 'resistance to flow' with particle size as described by Poppi et al. (1980). That the FOR from the rumen of the $2 \cdot 0-3.2 \mathrm{~mm}$ and $3 \cdot 2-4 \cdot 0 \mathrm{~mm}$ mesh particle-size groups were greater than zero is consistent with the passage of whole cereal grains from the rumen of cattle (Toland, 1976); feeding of whole grain would increase the rumen pool size of this group of particles and hence their flow from the rumen.

The FOR values of the $0.25-0.5 \mathrm{~mm}$ mesh particle group were considerably less $(0.66$ and 0.81 ) than the FOR of ${ }^{51} \mathrm{CrEDTA}$ determined in centrifuged rumen fluid for the groundand long-hay diets. It therefore appears that the FOR of even the smaller particle groups was considerably less than that of water, and that a water-soluble marker would not be an accurate indicator of their movement from the rumen. The observation that the FOR values of ${ }^{51} \mathrm{CrEDTA}$ measured in centrifuged rumen fluid and ${ }^{103} \mathrm{Ru}-\mathrm{P}$ in mixed digesta were not correlated $(r 0.34, n 16, P>0.05)$ in the present experiment also lends support to the concept that the FOR of the smaller particles separable by sieving may not directly depend on the FOR of water from the rumen.

The particles passing through the $0.25 \mathrm{~mm}$ mesh screen accounted for $0.34-0.38$ of the DM of the small-particle pool in the rumen and, even if their FOR was only one-half that of the rest of the small-particle pool, exit from the rumen in this fraction would be substantial. It is, therefore, of importance to attain a reliable estimate of the rumen FOR of very small particles.

\section{Lignin as a measure of FOR of particles moving from the rumen}

The FOR of lignin in mixed rumen digesta has been used (Minson, 1966; Poppi et al. $1981 \mathrm{a}$ ) as an estimate of the FOR of indigestible feed residues from the rumen. The FOR calculated in this way will be influenced by both the rate of removal of lignin in small particles and the proportion of the total rumen lignin that is in the particles small enough to be likely to move from the rumen. The FOR of only that lignin in the rumen small-particle pool will be a more accurate measure of the FOR of the particles actually passing from the rumen than the FOR of lignin in mixed rumen digesta despite the passage of a few large particles. In support of this argument, in the present experiment the FOR of lignin in the rumen small-particle pool $(1 \cdot 07 / \mathrm{d})$ was similar to the mean FOR of the $2 \cdot 0-3 \cdot 2,1 \cdot 0-2 \cdot 0$, $0.7-1.0,0.5-0.7$ and $0.25-0.5 \mathrm{~mm}$ mesh particle groups $(1.17 / \mathrm{d})$ and to the mean of these groups weighted for their relative pool sizes in the rumen $(1 \cdot 12 / d)$. In contrast, calculation on the basis of lignin in mixed rumen digesta reduced the estimate of FOR by nearly half.

The present study shows that with steers in steady-state conditions, the turnover of large particles in the rumen and the FOR from the rumen of digesta particle groups of various sizes could be estimated simply and directly from measurements of intake, faecal output, intestinal DM digestion and particle size distribution in boluses, rumen digesta and faeces. This approach would not, however, allow separate estimation of the FOR of the individual components of mixed diets. Also, due to the necessary assumption that the various particle groups in the rumen could be described by first-order kinetics, considerable error could be introduced in the absence of steady-state conditions. 
For $7 \mathrm{~d}$ there was a constant distribution of ${ }^{103} \mathrm{Ru}-\mathrm{P}$ among various particle-size groups in the rumen with 0.3 of the marker being associated with the large-particle pool for which there was only negligible flow from the rumen, and 0.5 was associated with the very small particles for which FOR is not yet known. Consequently, the FOR of ${ }^{103} \mathrm{Ru}-\mathrm{P}$ would be substantially influenced by the FOR of the rumen small-particle pool but it cannot be presumed that the ${ }^{103} \mathrm{Ru}-\mathrm{P}$ FOR is a direct measure of the small-particle FOR.

Partial financial assistance provided by the Natural Sciences and Engineering Research Council of Canada and the Agricultural Research Council of Alberta is gratefully acknowledged. The authors also wish to thank Mr J. Francis for care of the experimental animals, Mr B. V. Turner for assistance with radioactivity measurements and $\mathrm{Mr} \mathrm{R}$. Weingardt for assistance with statistical analysis.

\section{REFERENCES}

Balch, C. C. \& Campling, R. C. (1962). Nutrition Abstracts and Reviews 32, 669-686.

Beever, D. E., Coehlo da Silva, J. F., Prescott, J. H. D. \& Armstrong, D. G. (1972). British Journal of Nutrition 28, 347-356.

Beever, D. E., Osbourn, D. F., Cammell, S. B. \& Terry, R. A. (1981). British Journal of Nutrition 46, $357-370$.

Binnerts, W. T., van't Klooster, A. Th \& Frens, A. M. (1968). Veterinary Record 82, 470.

Bird, P. R. \& Fountain, R. D. (1970). Analyst (London) 95, 98-102.

Blaxter, K. L., Graham, N. McC. \& Wainman, F. W. (1956). British Journal of Nutrition 10, 69-91.

Bull, L. S., Rumpler, W. V., Sweeney, T. F. \& Zinn, R. A. (1979). Federation Proceedings 38, 2713-2719.

Campling, R. C. \& Freer, M. (1962). British Journal of Nutrition 16, 507-518.

Dixon, R. M., Kennelly, J. J. \& Milligan, L. P. (1983). British Journal of Nutrition 49, 463-473.

Dobson, A., Sellers, A. F., \& Gatewood, V. H. (1976). American Journal of Physiology 231, 1588-1594.

Dobson, A., Sellers, A. F. \& Shaw, G. T. (1970). Journal of Applied Physiology 28, 100-104.

Ellis, W. C., Matis, J. H. \& Lascano, C. (1979). Federation Proceedings 38, 2702-2706.

Evans, E. W., Pearce, G. R., Burnett, J. \& Pillinger, S. L. (1973). British Journal of Nutrition 29, 357-376.

Faichney, G. J. (1975). In Digestion and Metabolism in the Ruminant, pp. 277-291 [I. W. McDonald and A. C. I.

Warner, editors]. Armidale, Australia: University of New England Publishing Unit.

Faichney, G. J. (1980). Australian Journal of Agricultural Research 31, 1129-1137.

Faichney, G. J., Beever, D. E. \& Black, J. L. (1980-1981). Agricultural Systems 6, 261-268.

Faichney, G. J. \& Griffiths, D. A. (1978). British Journal of Nutrition 40, 71-82.

Goering, H. K. \& Van Soest, P. J. (1970). Agricultural Handbook 37. Washington, DC: United States Department of Agriculture.

Grovum, W. L. \& Williams, V. J. (1973). British Journal of Nutrition 30, 313-329.

Harrison, D. G., Beever, D. E., Thompson, D. J. \& Osbourn, D. F. (1975). Journal of Agricultural Science, Cambridge 85, 93-101.

Harrison, D. G. \& McAllan, A. B. (1980). In Digestive Physiology and Metabolism in Ruminants, pp. $205-226$

[Y. Ruckebusch and P. Thivend, editors]. Lancaster: MTP Press Ltd.

Hecker, J. F. (1969). Australian Veterinary Journal 45, 293-294.

Hungate, R. E. (1966). The Rumen and its Microbes, London: Academic Press.

Hunter, R. A. \& Siebert B. D. (1980). Australian Joumal of Agricultural Research 31, 1037-1047.

Jones, J. R. \& Moseley, G. (1977). Laboratory Practice 26, 687-689.

Kellaway, R. C., Beever, D. E., Thomson, D. J., Austin, A. R., Cammell, S. B. \& Elderfield, M. L. (1978). Journal of Agricultural Science, Cambridge 91, 497-503.

Kennedy P. M. (1982). Journal of Animal Science 55, 1190-1199.

Kennedy, P. M., Christopherson, R. J. \& Milligan, L. P. (1982). British Journal of Nutrition 47, $521-535$.

Lemerle, C., Murray, R. M. \& Leng, R. A. (1980). Proceedings of the Australian Society of Animal Production 13,454

Milligan, L. P., Kennedy, P. M. \& Christopherson, R. J. (1980). Canadian Journal of Animal Science 60, 1049.

Minson, D. J. (1966). British Journal of Nutrition 20, 765-773.

Nolan, J. V. \& Leng, R. A. (1972). British Journal of Nutrition 27, 177-194.

Pearce, G. R. (1967). Australian Journal of Agricultural Research 18, 119-125.

Pearce, G. R. \& Moir, R. J. (1964). Australian Journal of Agricultural Research 15, 635-644.

Poppi, D. P., Minson, D. J. \& Ternouth, J. H. (1981 a). Australian Journal of Agricultural Research 32, 109-121.

Poppi, D. P., Minson, D. J. \& Ternouth, J. H. (1981 b). Australian Journal of Agricultural Research 32, $123-137$.

Poppi, D. P., Norton, B. W., Minson, D. J. \& Hendricksen, R. E. (1980). Journal of Agricultural Science,

Cambridge 94, 275-280. 
Redman, R. G., Kellaway, R. C. \& Leibholz, J. (1980). British Journal of Nutrition 44, 343-354.

Rogers, J. A., Marks, B. C., Davis, C. L. \& Clark, J. H. (1979). Journal of Dairy Science 62, 1599-1605.

Shipley, R. A. \& Clark, R. E. (1972). Tracer Methods for In Vivo Kinetics, London: Academic Press.

Snedecor, G. W. \& Cochran, W. G. (1967). Statistical Methods, 6th ed. Ames, Iowa, USA: Iowa State University Press.

Sriskandarajah, N., Kellaway, R. C. \& Leibholz, J. (1982). British Journal of Nutrition 47, 553-563.

Sutherland, T. M. (1976). In Reviews in Rural Science, Vol. 2, pp. 65-72 [T. M. Sutherland, J. R. McWilliam and R. A. Leng, editors]. Armidale, Australia: The University of New England Publishing Unit.

Tan, T. N., Weston, R. H. \& Hogan, J. P. (1971). International Journal of Applied Radiation and Isotopes 22, 301-308.

Toland, P. C. (1976). Australian Journal of Experimental Agriculture and Animal Husbandry 16, 71-75.

Tomas, F. M. \& Potter, B. J. (1975). Australian Journal of Agricultural Research 26, 585-598.

Van Soest, P. J. (1982). Nutritional Ecology of the Ruminant. Corvallis, Oregon, USA. O\&B Books Inc.

Walker, D. J. \& Nader, C. J. (1975). Australian Journal of Agricultural Research 26, 689-698.

Warner, A. C. I. (1969). Veterinary Record 84, 441-442. 